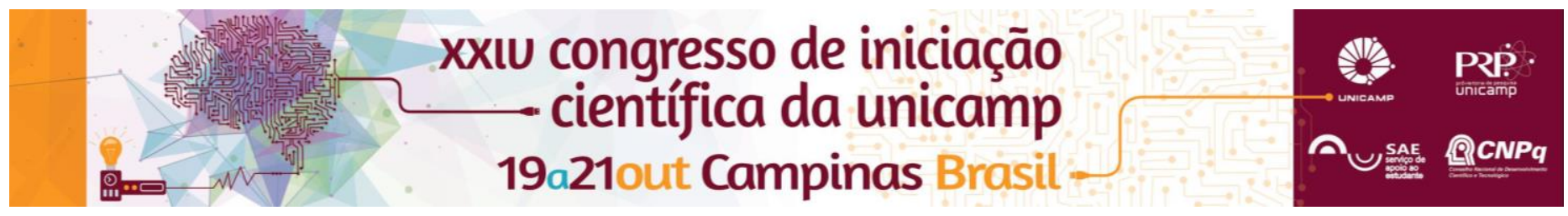

\title{
EFEITO DO BUTIRATO SOBRE OS ASPECTOS METABÓLICOS, MORFOMÉTRICOS E DE CITOARQUITETURA DO PÂNCREAS ENDÓCRINO DE CAMUNDONGOS OBESOS E PRÉ- DIABÉTICOS.
}

\author{
Letícia C. S. Monteiro*, Valquiria A. Mateus, Carla B. Collares-Buzato
}

\begin{abstract}
Resumo
A diabetes melito tipo 2 é uma síndrome endócrino-metabólica caracterizada pela hiperglicemia associada à resistência periférica à insulina. É conhecido que, em um estado pré-diabético, a célula beta pancreática apresenta uma resposta adaptativa compensatória, podendo sofrer hiperplasia e hipertrofia. Estudos tem demonstrado um efeito antidiabetogênico do butirato de sódio quando associado a uma dieta hiperlípidica. O objetivo deste trabalho foi analisar o efeito do butirato como suplemento de uma dieta hiperlípidica ou da ração padrão sobre os parâmetros metabólicos e a estrutura e morfometria do pâncreas endócrino de camundongos da linhagem C57.
\end{abstract}

Palavras-chave: diabetes melito tipo 2, butirato de sódio, célula beta pancreática, dieta hiperlipídica

\section{Introdução}

A diabetes melito é uma síndrome que compromete o metabolismo de carboidratos, lipídios e proteínas, resultante tanto da ausência da secreção de insulina, quanto da resistência periférica a tal hormônio (1). É conhecido que, em um estado pré-diabético, as células beta pancreáticas apresentam alta plasticidade funcional e estrutural compensatória. Estudos tem demonstrado que o butirato de sódio apresenta um efeito anti-diabetogênico quando acompanhado a uma dieta hiperlípidica (2). O objetivo do presente trabalho foi analisar o efeito do butirato como suplemento $(5 \% \mathrm{~g} / \mathrm{g})$ de uma dieta hiperlípidica (21\%g de lipídios) ou da ração padrão $(4.5 \% \mathrm{~g}$ de lipídios) sobre os parâmetros metabólicos e a estrutura e morfometria do pâncreas endócrino de camundongos machos da linhagem C57.

\section{Resultados e Discussão}

Os animais submetidos à dieta hiperlípidica (D) por 60 dias apresentaram um significativo ganho de peso (grupo $\mathrm{D}$, ganho de $45,5 \%$ vs grupo controle (C) de 6,07\%), bem como um ganho de tecido adiposo visceral significativamente maior $(p<0,001)$. Ainda, esses animais tratados mostraram um aumento significativo da glicemia e insulinemia em jejum e pós-prandial $(p<0,001)$ acompanhado por uma resistência periférica à insulina, como revelado pelo teste de ITT, em comparação ao grupo controle (C). Essas alterações dos parâmetros metabólicos analisados no grupo $D$, indicando 0 estabelecimento de um estado de pré-diabetes nesses animais, corroboram dados anteriores (3). O efeito antidiabetogênico do butirato de sódio foi observado no grupo exposto à dieta hiperlípidica acompanhada do butirato de sódio (DB), visto que houve uma melhora significativa dos parâmetros analisados neste grupo em relação ao grupo D. Tais efeitos do butirato não estão relacionados com alterações no consumo da ração, pois o consumo, medido em kcal, nos dois grupos (D e DB), foi semelhante, demonstrando que 0 não desenvolvimento do estado pré-diabético no grupo DB foi devido a efeitos diretos do butirato sobre a homeostase glicêmica. Por outro lado, o tratamento com butirato per se (grupo $\mathrm{CB}$, que recebeu ração padrão + butirato) não induziu alterações significativas nos vários parâmetros analisados quando comparado com o grupo C. É sabido que durante a pré-diabetes ocorre uma resposta DOI: 10.19146/pibic-2016-50770 compensatória da célula beta, que inclui hiperplasia/hipertrofia desse tipo celular, de forma a compensar os altos níveis glicêmicos do organismo (3). Por esse motivo, foram realizadas análises morfométricas em cortes histológicos do pâncreas, imunomarcados para insulina, nos vários grupos experimentais. Foi observado um aumento significativo $(p<0,0001)$ do volume relativo das células beta pancreáticas no grupo $\mathrm{D}$ em relação ao grupo $\mathrm{C}$; entretanto tal aumento não foi observado no grupo DB, indicando um efeito inibidor do butirato sobre a expansão da massa de células beta. Em relação à citoarquitetura da ilhota (caracterizada pela distribuição diferencial das células beta no centro da ilhota e da células alfa na periferia), a exposição à dieta hiperlípidica suplementada ou não com butirato não provocou diferenças significativas na disposição das células. Entretanto, a deposição de tecido adiposo intrapancreático observada no grupo $D$ foi significativamente reduzida com a suplementação do butirato como verificado no grupo DB. $(P<0,0001)$.

\section{Conclusões}

Foi observado um efeito benéfico e protetor do butirato de sódio em relação às alterações metabólicas induzidas pela dieta hiperlípidica, inibindo o desenvolvimento da resistência periférica à insulina e de alterações morfométricas compensatórias do pâncreas endócrino.

\section{Agradecimentos}

Apoio Financeiro: CNPq (Bolsa PIBIC para aluna LCSM*; Bolsa Produtividade 2 - CBCB), FAPESP e CAPES.

Procedimentos experimentais aprovados pelo Comitê de Ética Animal - CEUA/IB/UNICAMP - Protocolo\# 3439-1.

(1)American Diabetes Association. (2013). Diagnosis and classification of diabetes mellitus. Diabetes Care 36 Suppl 1, S67-13.

(2)Canani, R.B.; Di Costanzo, M.; Leone, L.; Pedata, M.; Meli, R.; Calignano, A. (2011) Potential beneficial effects of butyrate in intestinal and extraintestinal diseases. World J. of Gastroenterology 17, 1519-1528

(2)Gao, Z.; Yin, J.; Zhang, J.; Ward, R.E.; Martin, R.J.; Lefevre, M.; Cefalu, W.T.; Ye, J. (2009) Butyrate improves insulin sensitivity and increases energy expenditure in mice. Diabetes 58, 15091517

(3)Oliveira, R.B.; Carvalho, C.P.F.; Polo, C.C.; Dorighello, G.G.; Boschero, A.C.; Oliveira, H.C.F.; Collares-Buzato, C.B. (2014) Impaired compensatory beta cell function and growth in response to high fat diet in LDL receptor knockout mice. Int. J. Exp. Pathol. 95(4), 296-308. 